\title{
Stefan Szolc-Rogoziński: un viajero polaco en el golfo de Guinea
}

\author{
Stefan Szolc-Rogoziński: \\ A Polish Traveler in the Gulf of Guinea
}

\author{
IÑAKI TOFIÑO QUESADA \\ Universidad Autónoma de Barcelona, España
}

Resumen: El artículo revisa los textos publicados tras la expedición del polaco Stefan Szolc-Rogoziński al golfo de Guinea (1882-1885) por dos de sus protagonistas y por la esposa de Szolc-Rogoziński, con el fin de investigar las afirmaciones que indican que se trataba de una expedición para establecer una colonia polaca en Camerún. Asimismo, se estudia el intercambio de información en las revistas geográficas de finales del siglo XIX y su función propagandística.

Palabras clave: Camerún; Guinea española; Polonia; colonialismo; literatura colonial.

Abstract: This paper reviews the texts published after Polish navy officer Stefan Szolc-Rogoziński’s expedition to the Gulf of Guinea (1882-1885) by two of its members and by his wife, and seeks to investigate the claims that this mission was intended to establish a Polish colony in Cameroon. It also studies the exchange of in-

Recepción: 22 de abril de 2020. / Aceptación: 28 de julio de 2020.

D.R. ${ }^{\odot}$ 2021. Estudios de Asia y África Licencia Creative Commons Atribución-NoComercial-SinDerivar (CC BY-NC-ND) 4.0 Internacional 
formation in late-nineteenth-century geographical journals and its propagandistic role.

Keywords: Cameroon; Spanish Guinea; Poland; colonialism; colonial literature.

\section{Introducción}

En septiembre de 1881, un joven meteorólogo polaco, Leopold Janikowski, respondía a un anuncio publicado en la revista $W e^{-}$ drowiec por un desconocido Stefan Szolc-Rogoziński, "oficial de la armada, miembro de la sociedad geográfica de París y del club africano de Nápoles" (imagen 1), ${ }^{1}$ que buscaba compañeros de viaje para una expedición de un año cuyo objetivo era la creación de una estación geográfica en la bahía de Ambas, la exploración de las tierras altas de Camerún y la penetración del área en busca del lago Liba. Según Szolc-Rogoziński (1881), “si el proyecto genera resultados, veremos aumentar el número de voces polacas en el coro de opiniones del mundo científico y 'Dios bendecirá' nuestra sociedad". ${ }^{2}$

La mayoría de los autores que han investigado esta expedición se inclinan a pensar que, en realidad, las pretensiones de Szolc-Rogoziński consistían en crear una patria libre, una colonia polaca en África que acogiera a emigrantes polacos (Baginski $1944,72)$ y cuyo éxito probara la aptitud de Polonia para disponer de un estado propio y regirse por sí misma (Rhode 2013, 32). Otros, en cambio, a la vista de los documentos de los que disponemos, consideran que esa lectura quizá no sea más que una tergiversación auspiciada por la Liga Morska i Kolonialna [Liga Marítima y Colonial], organización patriótica que, entre 1930 y 1939, intentó buscar lugares adecuados para una posible

1 „Ofic. mar., czl. tow. geogr. w Paryżu i klubu afryk. w Neapolu”. Ésta y las traducciones siguientes son obra del autor del artículo, realizadas con la ayuda de un motor de traducción automática.

${ }^{2}$,Jeżeli projekt, przejdzie w czyn uwieńczony rezultatami, to w chórze opinii świata naukowego, usłyszymy, za powiększenie w nim liczby imion polskich, zapewne $\mathrm{i}$ «Bóg zapłać» naszego społeczeństwa”. 


\section{Imagen 1. Anuncio de Stefan Szolc-Rogoziński publicado en la revista Wędrowiec}

\section{Propozycya.}

Zamier/ająe w kwietniu roku przyszłego wy. ruszyć do kamejońskiéj zatoki (Afryka zash.) i, pozostawiwszy w górach tego\% imienia stacyą geograficznă, puścić się na Wschód kontynentu dla stwierdzenia istnienia jeziór Tuba $\mathrm{i}$ ich hydrograficznego połaczenia z zachodnim oceanem. z radościa powitalbym pomięlzy zjerlnoezonemi siłami méj wyprawy towarzysza podrósy z ojczystéj niwy, który zecheialby podzielié ze mną trudy i owoce.

Przecian czasu niezbeduy dla ekspedycyi oceniam na jeden rok muiéjwięcéj, udział zaśs materyalny wynosić będzie 2000 rs. (5,000 franków).

Uway̆jac za zbyteozne wyjaśnianie ile wazny odpowiedzi na liozne i dawne pytania maja dać nam tajemnicze jeziora, rachuje właśnie najpociąg ku sarnemu przedmiotowi; jezeli projekt, przejdzie w czyn uwienczony rezultatami, to w chórze opinii świata naukowego, uslyszymy, za powiększenie w nim liczby imion polskich, zapewne i „Bóg zapłac "“ naszego społerzeństiwa.

Pozostawiajųc bližsze porozumienie się szersøej korespondeneyi, składam adres swój w redakcyi ,Wędrowerd."

Stofikn-Szolc-Royoziniski.

Otic. mar., czt. 1ow. greogr. w Paryźzu i klubu alryk. w Netpolu.

Dominio público.

expansión colonial de Polonia en Brasil, Liberia o Madagascar, por ejemplo (Będkowski 2016). ${ }^{3}$

El mayor argumento a favor de una lectura colonialista de la expedición son las memorias de Leopold Janikowski, $W$

${ }^{3}$ Para más información sobre los objetivos coloniales de Polonia en el periodo de entreguerras y el papel de la Liga Colonial y Marítima, véanse Hunczak 1967, y Nadolska-Styczyńska 2007. 
dżunglach Afryki. Wspomnienia z polskiej woyprawey afrykańskiej w latach 1882-1890 [En las selvas de África. Recuerdos de una expedición africana polaca en los años 1882-1890], publicadas en 1936 por la Liga Marítima y Colonial, que exponen muy claramente los supuestos objetivos del viaje:

1. Asentamiento en las montañas de Camerún (en la bahía de Biafra), para explorar las montañas y organizar recorridos geográficos en el interior del continente tanto como fuera posible.

2. Exploración de la costa occidental de África y las áreas de Liberia a Camerún aún no ocupadas por ningún país, para colonizarlas y adquirirlas y formar así la primera colonia polaca independiente.

Estos planes siempre estuvieron guiados por la fe en el renacimiento de Polonia (Janikowski 1936, 7). ${ }^{4}$

Además de tener en cuenta la posible censura zarista sobre el anuncio o sobre los testimonios publicados en forma de libro o en revistas de geografía tras el regreso de la expedición, hay que considerar la situación geopolítica de Polonia y de Camerún en aquel momento. Polonia era una entidad inexistente políticamente, desmembrada entre tres estados europeos: Rusia, Prusia y el Imperio austrohúngaro; Camerún, por su parte, era, a ojos de los europeos, terra nullius, y tanto Gran Bretaña como Prusia parecían tener interés en apropiárselo. Todavía no se había celebrado la conferencia de Berlín, que implicaría el reparto de África entre las diversas potencias colonizadoras, y la llegada del grupo de polacos supuso un verdadero quebradero de cabeza para el canciller Bismarck, que veía en SzolcRogoziński un agente al servicio de los intereses británicos.

${ }^{4}$ „i) Osiedlenie się w górach Kameruńskich (w zatoce Biafra), poznanie gór i urządzanie wycieczek geograficznych, możliwie najdalej w głąb kontynentu. ii) Zbadanie zachodniego brzegu Afryki i zorientowanie się, czy tereny, leżące od Liberji aż do Kamerunu, niezajęte dotąd przez żadne z państw, nadawałyby się dla kolonizacji i nabycia, celem utworzenia pierwszej niezależnej Kolonji Polskiej. Planom tym zawsze przyświecała myśl i wiara w odrodzenie Polski”. 
Además, para acabar de complicar las cosas, algunos líderes locales firmaron tratados de cesión de soberanía con más de una potencia colonial; así, el jefe Monika de Boando rubricó un tratado con Szolc-Rogoziński, que actuaba en nombre de los británicos y, en concreto, para el Council of the Colony of Victoria, y otro con los suecos Knut Knutson y Georg Waldau (sobre su acción en África, véase Knutson 2002, 49-51), que operaban en nombre de Prusia (Betley 1996, 127).

En cualquier caso, lo que sí está claro es que, en la década de 1930, se produjo una relectura en clave patriótica de una expedición que, en sí misma, resultó bastante desastrosa. Algo parecido a lo que ocurrió en la España de los años 40-50 respecto a la expedición de Manuel Iradier. Las correrías africanas de unos visionarios que actuaban por su cuenta con escasos recursos económicos se presentaron décadas después como grandes gestas imperiales.

El propósito de este artículo es recuperar la memoria de esa expedición y presentar la documentación que hay al respecto y los textos escritos por los que participaron en ella, así como analizar las coordenadas geopolíticas que llevaron a su fracaso. Además, intento destacar las conexiones de la expedición polaca con la isla de Fernando Poo, que en aquel momento era una colonia española, para contribuir a la construcción de lo que se ha denominado global hispanophone, un ámbito de trabajo que incorpora las culturas y las experiencias históricas del norte de África, Guinea Ecuatorial, Filipinas y otros territorios que, en su momento, formaron parte del Imperio español (CampoyCubillo y Sampedro Vizcaya 2019, 1), para subrayar la pluralidad de voces, espacios y lenguas presentes en él y expandir los límites tradicionales de los estudios hispánicos.

\section{La expedición}

El polaco Stefan Szolc-Rogoziński (1861-1896), militar y explorador, nació en Kalisz, Polonia central, en una familia protestante. Era hijo de Ludwik Scholtz, un industrial local, y de 
Malwina Rogoziński, hija de un conocido abogado de Varsovia. Bajo la influencia de su madre, la familia lentamente se fue polonizando, aunque el alemán era su idioma materno. De adulto, Stefan cambió su apellido paterno a Szolc y agregó el apellido de soltera de su madre.

En 1878 se presentó como voluntario en la academia naval de Kronstadt. En abril de 1880 aprobó el examen y recibió el rango de oficial. Pronto realizó su primer viaje a Vladivostok y su primer viaje alrededor del mundo, durante el cual visitó Marruecos y Argel. En mayo de 1881, después de llegar a París, ingresó en la Société géographique, y después desarrolló los planes para viajar a Camerún, momento en que publicó su anuncio. Intentó obtener ayuda económica de su padre, pero fracasó, por lo que tuvo que utilizar la herencia de su madre para financiar la expedición y pedir a los voluntarios una contribución económica para sufragar los gastos.

Compró el barco Łucja Małgorzata en Francia y el 13 de diciembre de 1882 abandonó El Havre en compañía del geólogo Klemens Tomczek (1860-1884), que fallecería durante la expedición; del meteorólogo Leopold Janikowski (1855-1942) y de dos hombres más. ${ }^{5}$ Viajaron a África y permanecieron en el golfo de Guinea entre 1882 y 1885 . Tras pasar por el puerto inglés de Falmouth, Madeira, las islas Canarias y Liberia, el 16 de abril de 1883 llegaron a Santa Isabel de Fernando Poo, punto que tomaron como base de su expedición.

Poco después, los viajeros compraron la isla de Mondoleh frente a la costa de Camerún, donde establecieron una estación científica. Mientras Szolc-Rogoziński cartografiaba el río Mungo, Janikowski se dedicó a acondicionar la estación de Mondoleh. También aprovechó para estudiar al pueblo bubi de Fernando Poo, estudios pioneros que después publicaría en diversas revistas geográficas europeas.

${ }^{5}$ Las fuentes hablan de Władysław Ostaszewski y Walery Tomaszewski o Ludwik Hirszenfeld, pero ni Szolc-Rogoziński ni Janikowski los citan en sus memorias, de manera que es probable que se produjera algún conflicto entre ellos y los autores decidieran silenciar su memoria. 
En 1884, Szolc-Rogozińnki y Janikowski viajaron a Gabón, donde recogieron material antropológico y etnográfico, y convencieron al vicario apostólico, el espiritano Pierre Marie Le Berre, para que enviara misioneros católicos a la isla de Mondoleh y, por ende, a Camerún. Se enviaron dos misioneros a la isla (Różański 2000, 84), pero las reticencias alemanas hicieron que su actividad fuera muy limitada. Más tarde, el canciller Bismarck aceptó la presencia de clérigos de la Sociedad del Apostolado Católico (palotinos), cuyos misioneros desplazados a África acabaron deportados a la isla de Fernando Poo durante la Primera Guerra Mundial, tras la invasión aliada a Camerún, un episodio que provocó diversas fricciones entre las cancillerías aliadas y el gobierno de Madrid, neutral durante la contienda.

Si en el aspecto religioso la expedición no tuvo demasiado éxito, mucho menos lo tuvo en el aspecto político. Tomczek falleció de malaria y, en julio de 1884, Szolc-Rogoziński y Janikowski se encontraron con buques alemanes en aguas de Camerún. Fueron llevados a declarar a Bimbia, un estado independiente que los alemanes se habían anexionado, donde en 1858 se había establecido el misionero baptista británico Alfred Sacker tras ser expulsado de Fernando Poo por las autoridades españolas, que pretendían eliminar así la influencia protestante en la isla. Ese hecho no impidió que Janikowski y Szolc-Rogoziński se unieran al periodista alemán Hugo Zöller en una expedición a la cumbre del volcán Camerún en diciembre de 1884 . Fue el primer viaje polaco y el tercero europeo al monte, después del de Richard Burton en 1860 y del de Thomas James Comber en 1878.

Una entrevista entre los ministros de Asuntos Exteriores, el británico George Granville Leveson-Gower y el alemán Herbert von Bismarck, que buscaban a toda costa evitar el enfrentamiento entre los dos países en la zona, acabó con las ambiciones polacas de establecerse en la costa africana. Camerún se convirtió en un protectorado alemán. Sin un estado que los respaldara, los expedicionarios regresaron a Europa en el 
verano de 1885. Primero fueron a Londres y a París, donde dieron algunas conferencias sobre su viaje. Más tarde, la expedición regresó a Polonia.

Leopold Janikowski volvió a África a principios de 1887, esta vez para establecerse cerca de los montes de Cristal en el territorio de los fangs. En diciembre de 1889 regresó a Varsovia. Con su colección de objetos africanos creó una exposición etnográfica en el Museo de Industria y Agricultura de Varsovia, del que fue secretario, subdirector y director administrativo. En septiembre de 1939, el edificio del museo fue completamente destruido por los bombardeos y el fuego. Janikowski y su esposa pasaron la guerra en Zielonka, donde escondieron a ciudadanos judíos en el sótano bajo su cocina.

Por lo que respecta a Szolc-Rogoziński, en 1886 compró una finca de 500 ha en Fernando Poo para una futura plantación de cacao cuyos beneficios debían servir para financiar una segunda expedición africana. En enero de 1887 inició la construcción de una casa con los materiales que había llevado desde Mondoleh (Franczyk 2017). De vuelta a Polonia, en agosto de 1888, se casó con la escritora Helena Janina Pajzderska, con la que regresó a Fernando Poo. Entre 1892 y 1893 viajó por Egipto.

Antes de morir, en 1893, Szolc-Rogoziński organizó sus colecciones etnográficas, que incluían elementos procedentes de Camerún, Gabón y Fernando Poo. Los artefactos etnográficos fueron entregados al Museo Técnico e Industrial de Cracovia, mientras que los antropológicos se depositaron en la Academia de Artes y Ciencias de Cracovia. Actualmente, la mayoría de los objetos de la expedición africana de Szolc-Rogoziński se encuentran en las colecciones del Museo Etnográfico de Cracovia.

\section{Textos}

Tras su regreso a Europa después de la fallida expedición, los dos viajeros llevaron a cabo una importante tarea de difusión 
de su viaje, como era costumbre entre los exploradores de la época, probablemente con la idea de movilizar a la opinión pública y recoger fondos para futuros viajes. En este sentido, disponemos de varios textos en diversos idiomas escritos por personas vinculadas a la expedición y a sus consecuencias posteriores, como el asentamiento de Szolc-Rogoziński en Fernando Poo.

El primero en publicar fue el líder del proyecto, Stefan Szolc-Rogoziński, que en noviembre de 1885 llevaba a la imprenta su Voyage à la côte occidentale d'Afrique [Viaje a la costa occidental de África], las notas de una conferencia pronunciada en la Société de géographie commerciale de El Havre el 24 de noviembre de ese año. Después vendrían otra conferencia, Pod równikiem. Odczyty S. S. Rogozińskiego reypowiedziane w Sali Radnéj miasta Krakowa [Bajo el ecuador. Conferencia de S. S. Rogoziński pronunciada en la sala consistorial de la ciudad de Cracovia] (1886a); sus memorias, Wyprawa S. S. Rogozińskiego. Żegluga wzdtuż brzegów zachodniej A fryki na lugrze "Eucya-Matgorzata" 1882-1883 [Expedición de S. S. Rogoziński. Navegando por las costas de África occidental a bordo del "Łucya-Małgorzata"] (1886b) y un artículo publicado en el Boletín de la Sociedad Geográfica de Madrid en 1890, "El viajero polaco Rogozinski en Fernando Poo".

Por su parte, Leopold Janikowski publicó dos artículos, uno en francés y otro en castellano, prácticamente idénticos, en el Bulletin de la société de géographie de Paris y en la Revista de geografía comercial: "L'île de Fernando Poo. Son état actuel et ses habitants" (1886) y "La isla de Fernando Poo. Su estado actual y sus habitantes" (1887a y 1887b). Sus memorias no se publicaron hasta 40 años después, en un contexto histórico y social muy diferente, como hemos visto. Finalmente, cabe recordar el trabajo de Helena Janina Pajzderska, la esposa de Szolc-Rogoziński. Aunque ella no participó en la primera expedición africana de su marido, sí que le acompañó cuando se trasladó a vivir a Fernando Poo. Allí subieron al pico Basilé, ascensión que narró en francés para la Revue de géographie, "Une 
ascensión au pic Santa Isabel (Fernando Po)” (1892), y en polaco en el cuarto relato de su libro $Z$ dalekich ladów [De tierras lejanas] (1893), "Nad przepaściami” [Sobre los precipicios].

Lo interesante de todos estos textos es ver cómo tejen una red de información que resulta perfectamente controlada: lo que se cuenta, lo que no se cuenta, en qué idioma se cuenta y dónde se publica. Como es de suponer, no hay forma de saber si se trató de una decisión premeditada por su parte, pero es una muestra fascinante del discurso colonial europeo, que utilizaba todos los recursos a su alcance para buscar gloria y fama, pero también, no nos engañemos, recursos económicos para financiar nuevas expediciones, amparado por el supuesto carácter científico de sus publicaciones. Además, publicar en castellano o en francés les podía abrir las puertas del mecenazgo de Madrid o de París, que estaban afianzando su presencia colonial en el golfo de Guinea, donde se enfrentaban a las pretensiones alemanas.

Szolc-Rogoziński empieza prácticamente al bajar del barco. Publica en francés las notas de una conferencia pronunciada en El Havre, ciudad de la que había partido su expedición. El texto voluntariamente deja de lado cuestiones políticas o detalles geográficos: "No quiero molestarlos con la narración de los incidentes políticos en los que acabo de participar [...] Tampoco quiero entrar en detalles geográficos de mis exploraciones. Nos quedaríamos sin tiempo y me reservo esta tarea para un estudio especial” (Szolc-Rogoziński 1885, 26). ${ }^{6}$

A la espera de una futura publicación, se centra en la descripción del viaje y, sobre todo, en las maravillas de la civilización francesa en Grand-Bassam y Assinie. Habla también de Fernando Poo, probablemente porque se trataba de un territorio cercano a Gabón, colonizado por los franceses, y no duda en

${ }^{6}$ « Je ne veux pas vous importuner par la narration des incidents politiques auxquels je viens d'être mêlé [...] Je ne veux pas non plus entrer dans les détails géographiques de mes explorations. Le temps nous manquerait, et je réserve d'ailleurs cette tâche pour une étude spéciale ». 
confesar que "prefiero a los ingleses que a los alemanes" (SzolcRogoziński 1885, 26).?

Se trata de un texto que va a circular en los ambientes científicos y coloniales de la época, pues Amado Ossorio se referirá a él para refutarlo en un artículo de 1886, publicado en los Anales de la Sociedad Española de Historia Natural. El asturiano afirma que "bien merecen correctivo algunas de las erróneas afirmaciones que no há mucho publicó en una memoria leída en la Sociedad Geográfica de El Havre un viajero polaco" (Ossorio 1886, 291), y refuta las observaciones de Szolc-Rogoziński sobre la ausencia de "fetiches" entre los bubis y la falta también de una verdadera religión entre ellos, y sobre la soberanía única de Moka sobre la isla, "porque hay infinidad de pueblos que lo desprecian y otros donde ni siquiera ha llegado la noticia de su existencia" (293). En este sentido, Ossorio parece estar mejor informado que los polacos SzolcRogoziński o Janikowski, cuyos artículos se publicaron sin tener en cuenta esta información sobre las costumbres de los bubis de Fernando Poo proporcionada en los Anales.

El segundo texto, la conferencia pronunciada en Cracovia, publicado en polaco en 1886, incluye algunos de los acontecimientos descritos en la conferencia francesa y también promete un libro para el futuro, pero tiene un propósito explícito y específico: "Este trabajo [...] es sólo una descripción de la expedición y los eventos que la acompañaron durante los últimos meses de mi estancia en las costas de Camerún, errónea y completamente tergiversada en su momento por la prensa alemana" (Szolc-Rogoziński 1886a, 1). ${ }^{8}$

Efectivamente, incluye la descripción de los rifirrafes con los alemanes y los ingleses en la costa de Camerún y es, sobre todo, un homenaje a su compañero Tomczek, de quien no había hablado en su conferencia francesa y a quien no volverá

7 «Je préfère les Anglais aux Allemands ».

${ }^{8}$ „Niniejsza praca więc zawiera jedynie opis przebiegu wyprawy i zajść towarzyszących jej podczas ostatnich miesięcy pobytu mego u brzegów Kameruńskich, mylnie i zupełnie nieprawdziwie przedstawionych w swoim czasie przez prasę niemiecką". 
a referirse más tarde. Aquí contaba con la complicidad de los oyentes, polacos como él, pero en ningún momento habla de una posible idea de establecer una colonia polaca en África. Cracovia, que había sido una república entre 1815, tras el congreso de Viena, y 1846, garantizada por los tres países vecinos, Rusia, Prusia y Austria, formaba parte del Imperio austrohúngaro, y es de suponer que a la corte vienesa no le debía hacer mucha gracia oír hablar de una posible colonia africana bajo soberanía polaca.

Las memorias de Szolc-Rogoziński, publicadas en polaco en Varsovia también en 1886, curiosamente no se refieren en absoluto a los incidentes con británicos y prusianos, sino que son una descripción del viaje que incluye referencias a los protectorados franceses y británicos de la costa del golfo de Guinea. Un par de comentarios destacan por su novedad, ya que no habían aparecido en las dos publicaciones anteriores.

El primero es la referencia a unas supuestas demandas territoriales españolas sobre Agadir, ciudad a la que confunde con el asentamiento de Santa Cruz de la Mar Pequeña, ocupado por colonos canarios entre 1478 y 1527, que durante el siglo XIX se identificó con Ifni, más al norte, identificación que sustentó la demanda española de soberanía sobre ese territorio. Durante su paso por las Canarias, tuvo ocasión de conocer al general Valeriano Weyler y Nicolau, que ejercía como capitán general de las islas y del que explica que "me mencionó que en unos días partiría con una expedición militar a orillas del Sáhara marroquí para tomar en nombre del gobierno español uno de los puntos a los que España tiene derecho, la ciudad marroquí de Agadir, que en español significa Santa Cruz de la Mar Pequeña” (Szolc-Rogoziński 1886b, 100). ${ }^{9}$

Weyler nunca tomó Agadir, ni tan siquiera ocupó Ifni, donde la presencia española fue inexistente hasta 1934. Sin em-

${ }^{9}$ „Wspomniał mi, że i on za kilka lub kilkanaście dni wyruszy z ekspedycją wojskowego charakteru na brzegi marokańskiej Sahary, by zająć w imieniu rządu hiszpańskiego jeden z punktów, do których Hiszpania ma prawo. Jestto marokańska miejscowość Agadir, czyli ja k nazywają ją Hiszpanie Santa-Cruz-de-Mar-Pequena”. 
bargo, sería después capitán general de Cuba, donde ordenó la reconcentración de la población rural del occidente cubano en núcleos urbanos que se convirtieron en verdaderos campos de concentración (Stucki 2012), y capitán general de Cataluña, donde reprimió las protestas de la Setmana Tràgica de 1909 contra el envío de reservistas a combatir en el norte de África. También estuvo conectado con Fernando Poo, pues en 1905 presentó un proyecto para la adjudicación de concesiones territoriales en la Guinea continental en nombre de una futura compañía española de colonización, aunque finalmente el Muni no se adjudicó a ninguna empresa (Guerra Velasco 2018).

El segundo comentario fue sobre los beneficios que obtuvo la República de Liberia tras su independencia en 1847. En el caso de alguien que defendía las libertades de su país, lo lógico hubiera sido encontrar una defensa de la libertad liberiana; sin embargo, Szolc-Rogoziński parecía tener bastante claro que los africanos no eran capaces de gobernarse por sí mismos y que vivirían mejor a la sombra de la bandera de Estados Unidos:

El 26 de julio de 1847, el gobierno de Estados Unidos finalmente abandonó su protectorado y Liberia se declaró una república independiente. Aunque este cambio condujo al pueblo liberiano a hacer cosas estúpidas, resulta dudoso saber si les hubiera ido mejor si hubieran permanecido bajo la bandera estadounidense; la prosperidad del país sería mucho mayor bajo dicho gobierno y fuera de ella estaría protegida por la bandera de un Estado poderoso, en lugar de la bandera de una Liberia independiente, cuya impotencia ya les había afectado (Szolc-Rogoziński 1886b, 122). ${ }^{10}$

El último texto de Szolc-Rogoziński del que tengo noticia es un artículo publicado en el Boletín de la Sociedad Geográfica de Madrid en 1890, "El viajero polaco Rogozinski en Fernando

10 „Dnia 26 lipca 1847 r. rząd Stanów Zjednoczonych zwinął wreszcie swój protektorat i Liberya ogłosiła się niepodległą rzeczpospolitą. Jakkolwiek ta zmiana wbiła Liberyjczyków w durne, jestto jednak rzeczą bardzo wątpliwą czy przyniosła im korzyść, czy nie lepiej byliby zrobili, pozostając pod flagą amerykańską; dobrobyt kraju byłby w takim rązie o wiele większy, a na zewnątrz zasłaniałaby ich flaga potężnego państwa, zamiast flagi niepodległej Liberyi, której bezsilność dobrze już im się dała we znaki”. 
Poo". En la introducción explica que “organizó una expedición científica con el propósito de explorar los países que lindan con el golfo de Biafra, especialmente el macizo de Camarones y los territorios de Bekundu" (Szolc-Rogoziński 1890, 63). Ninguna referencia, pues, a supuestas veleidades coloniales polacas en África. De hecho, el artículo viene precedido por una introducción que lo presenta como "subteniente de la Marina imperial rusa”, y así es como los describirá a él y a su esposa toda la prensa española del momento, como súbditos del imperio ruso. En algunos casos se habla de su condición de polacos: "Esteban Rogozinski es natural de Polonia" (como en el artículo "Los esposos señores Rogozinski, excursionistas al pico de Santa Isabel de Fernando Poo", publicado el 22 de marzo de 1891 en La Ilustración Española y Americana), mientras que en otros se les describe recurriendo a los tópicos más manidos, como en un artículo publicado en La Dinastía el 23 de marzo de 1891: "M. Rogozinski y su intrépida consorte son rusos; basta verlos para adivinar en sus ojos la salvaje energía eslava; él es teniente de navío de la Marina de guerra de su país; ella, polaca de nacimiento, tiene un nombre como novelista, aunque literariamente se la conoce por Hayota".

El texto describe la ascensión que Szolc-Rogoziński realizó con Pajzderska al pico Basilé en 1888 e incluye multitud de datos meteorológicos y orográficos, así como alguna referencia a los habitantes de la isla y a la posible explotación del caucho local. Como se verá, a diferencia del texto de Pajzderska, pretende ser bastante aséptico y científico, como correspondía a una publicación especializada como el boletín de una sociedad geográfica.

El segundo superviviente de la expedición, Janikowski, publica casi simultáneamente dos artículos científicos justo después de las primeras conferencias de su compañero de viaje. Sin embargo, no habla de su travesía, sino que se refiere a un territorio conocido por sus lectores, la isla de Fernando Poo. ¿Se habían repartido las tareas o sencillamente cada cual prefirió escribir sobre un tema diferente? Quién sabe. 
Para Núria Fernández Moreno $(2013,25)$, este artículo y los de Navarro y Sorela "son los que proporcionan la información más precisa sobre las jefaturas políticas y la organización militar bubi del momento". ${ }^{11}$ Efectivamente, a falta de fuentes que no sean la memoria oral, estos textos europeos son el principal recurso informativo para entender el cambio dentro de la sociedad bubi de Fernando Poo que supuso la concentración de liderazgo en la figura del rey Moka. Janikowski describe esa organización, así como algunos elementos de la religiosidad bubi, su organización social o el papel de las mujeres.

Tanto el texto francés como el español, prácticamente idénticos, celebran la inteligente administración del rey Moka, una figura importante para el pensamiento colonial, puesto que permite "negociar" con un único representante de la población local y, además, es equiparable a la figura de un monarca europeo, de manera que simplifica la comprensión de una sociedad con múltiples jefaturas. La situación no era tan sencilla, y, tras la muerte de Moka, tuvieron lugar diversas luchas por el poder dentro de la sociedad bubi, que reaccionaba al contacto con los europeos y se ajustaba a la nueva situación.

Un apunte curioso que demuestra la circulación de estos textos entre las élites occidentales preocupadas por la colonización y la explotación de África es el resumen del texto francés que George Hulburt publicó en el Journal of the American Geographical Society of New York en 1887. Tras un apunte histórico sobre la oportunidad perdida por los británicos al no haber conseguido obtener la soberanía de la isla de Fernando Poo - "hace menos de cincuenta años estaba en poder de los ingleses, quienes ocasionalmente deben lamentarse de haberla dejado acabar en manos de España” (Hurlbut 1887, 71) - ${ }^{12}$ el geógrafo incluye un comentario a medio camino entre la erudición y la ironía cruel:

11 "Are the ones who provide the most precise information on the political chiefdoms and on Bubi military organization at that moment".

12 "Less than fifty years ago it was in the power of the English, who must occasionally regret having allowed it to slip from them into the hands of Spain". 
Se ha afirmado que la isla es, en general, un lugar saludable, pero tiene sus enfermedades, y el señor Janikowski nombra una con el misterioso término inglés de género amarillo [yellow gender].

A una raza de bobos confesos, cualquier distinción gramatical le debe parecer poco menos que una aparición divina, pero a otros hombres les resulta difícil oír hablar de un género de color amarillo, de una declinación morada o de una sintaxis carmesí.

Janikowski probablemente no esté familiarizado con el inglés oral. El nombre que oyó y que debería haber escrito era, sin duda, ictericia [yellow jaundice] (Hurlbut 1887, 74)..$^{13}$

Además de burlarse de los bubis, habitantes de la isla de Fernando Poo, ${ }^{14}$ Hulburt se ríe de la ignorancia de Janikowski y juega con la semejanza fonética en inglés de los términos 'gender' y 'jaundice' en un párrafo que bromea sobre las connotaciones de la palabra 'gender', en aquel momento tan sólo una categoría gramatical, ligada, por tanto, a la familia lingüística de términos como "declinación" o "sintaxis", los que pinta de color morado o carmesí. El error de Janikowski es flagrante y se reproduce sin reparo en las versiones francesa y española del texto:

Les habitants de Sainte-Isabelle connaissent encore certains fébrifuges locaux. Ils guérissent, une espèce de fièvre jaune, nommée par les Anglais «yellow gender », au moyen d'une plante parasite qui croit sur les arbres (Janikowski 1886, 574).

Los habitantes de Santa Isabel conocen también ciertos febrífugos locales. Curan una especie de fiebre amarilla, llamada por los ingleses " $y e$ llow gender", por medio de una planta parásita que crece en los árboles (Janikowski 1887a, 437).

13 "It has been said that the island is, on the whole, a healthy place, but it has its diseases, and to one of these M. Janikowski gives the mysterious English name of yellow gender. / To a race of self-confessed Boobis any kind of grammatical distinction may very well seem to be nothing less than a visitation of God; but other men find it difficult to form a conception of a yellow gender, or a purple declension, or a crimson syntax. / M. Janikowski is, probably, not familiar with spoken English. The name he heard and ought to have written was, undoubtedly, yellow jaundice".

${ }^{14}$ Se aprovecha de la semejanza fonéticas entre las palabras 'bubi' y 'boobi'. 
Tanto en inglés ('jaundice') como en castellano ('ictericia'), en francés ('ictère') o incluso en polaco ('zóttaczka'), el nombre del síntoma proviene del nombre del color que toman los tejidos de los pacientes, el amarillo. La diferencia es el origen de la palabra, francés en el caso de la lengua inglesa ('jaune'), griego

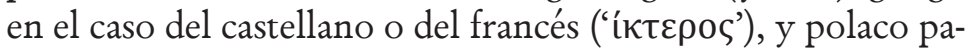
ra el término en la lengua materna del autor ('zótty'). Evidentemente, Janikowski no cayó en la cuenta de su error.

Mientras que sus textos "científicos" se publicaron justo después del final de la expedición a las costas camerunesas y no hablan para nada de ella, sus memorias se publicaron cuarenta años después. $W$ dżunglach Afryki es un resumen de la expedición a las costas del golfo de Guinea y no se aleja demasiado de lo expuesto por Szolc-Rogoziński en 1886, aunque es mucho más explícito sobre los objetivos de la expedición:

Cuando en 1880 conocí a Rogoziński y cuando me presentó sus planes de investigación científica, uno de cuyos objetivos principales, necesariamente ocultos, era encontrar un área adecuada para la colonización polaca como futuro refugio para aquellos que se encontraban material y espiritualmente controlados por nuestros tres divisores, este plan me embargó y me entregué a él con toda mi alma.

Sin embargo, el destino no nos permitió llevarlo a cabo. Perdimos el área más adecuada de Camerún, todavía no reclamada oficialmente por ningún país europeo, cuando los alemanes la ocuparon. Agradezco la ayuda y el cuidado prestados a nuestra expedición por la armada inglesa; ayudamos a los ingleses a apoderarse de las montañas del Camerún, por lo que fuimos perseguidos por Bismarck y la armada alemana; yo mismo fui bombardeado en el mar y arrestado de manera brutal (Janikowski 1936, 206-207). ${ }^{15}$

15 „Kiedy w 1880 r. poznałem Rogozińskiego i kiedy roztoczył on przede mną swoje plany badań naukowych oraz jeden z głównych celów, z konieczności ukrytych, a mianowicie wyszukanie odpowiedniego terenu dla kolonizacji polskiej, jako przyszłej ostoi dla tych, którym nietylko materjalnie ale i duchowo było za ciasno pod rządami trzech naszych zaborców, -plan ten porwał mnie, i oddałem mu się całą duszą. / Losy jednak, przeciwnie, nie pozwoliły nam tego planu przeprowadzić. Najodpowiedniejszy teren kameruński, wówczas jeszcze niezajęty urzędowo przez żadne z państw europejskich, był dla nas stracony, po zajęciu go przez Niemców. Wywdzięczając się za pomoc i opiekę, udzieloną naszej ekspedycji przez angielską 
Como hemos visto, sólo este texto explicita un supuesto objetivo de establecimiento colonial, más allá del interés científico, pero, teniendo en cuenta el momento en que se llevó a la imprenta, el público al que se destinaba y la organización que lo publicó, resulta fácil pensar que se trata de una reescritura del pasado. Probablemente no sepamos nunca qué pasaba por la mente de Szolc-Rogoziński y de sus compañeros, pero está claro lo que pretendía Janikowski cuando en 1936 recordaba la expedición y a sus compañeros fallecidos, uno en África y el otro en Europa: “Tal vez viviré para ver ese momento alegre en que la bandera polaca ondee sobre la primera colonia polaca y ese día solemne será como una corona de flores sobre las tumbas de los valientes pioneros" (Janikowski 1936, 207). ${ }^{16}$

Para concluir nuestro recorrido por los textos de autores polacos vinculados a la isla de Fernando Poo, no se puede olvidar la narración de Helena Janina Pajzderska, la esposa de Szolc-Rogoziński. Su primera publicación aparece en una revista científica, la Revue de géographie, firmada por HélèneJeanne de Rogozinski (Pajzderska 1892), un texto que más tarde reutilizará para publicarlo en polaco como el cuarto relato de su libro $Z$ dalekich ladów (Pajzderska 1893). No hay demasiadas diferencias entre uno y otro, pero el contexto sí que resulta destacable. En el caso de la Revue, su narración se codea con otras publicaciones sobre exploración y geografía, no únicamente africana sino también europea, americana o asiática, que por esa compañía le otorgan el estatus de publicación científica. En cambio, el texto en polaco se inscribe en un proyecto literario diferente, que incluye cierta crítica $a$ posteriori del colonialismo europeo.

\footnotetext{
Marynarkę Wojenną, daliśmy wzamian pomoc Anglikom przy zajęciu gór Kameruńskich, za co byliśmy przez Bismarcka i Marynarkę niemiecką prześladowani; ja sam, osobiście, w brutalny sposób byłem ostrzeliwany na morzu i aresztowany”.

${ }^{16}$ „Może dożyję jeszcze tej radosnej chwili, gdy flaga Polski powieje nad pierwszą polską kolonją, a ów uroczysty dzień będzie wieńcem na grobach dzielnych pionierów”.
} 
"Nad przepaściami" es el relato de su ascensión al pico Basilé, llamado Clarence Peak cuando ella lo visitó en compañía de su marido. Rogoziński, a quien la autora-narradora se refiere por el apellido, ya había subido al monte Camerún en el continente y quería confirmar las mediciones del botánico alemán Gustav Mann, director de los reales jardines botánicos de Kew, que daba una altitud diferente a la indicada en las cartas náuticas. Hajota (seudónimo de Pajzderska), por su parte, se entusiasma con la idea tras leer Abeokuta and the Cameroon Mountains de Richard Burton y sabe de la expedición de Julián Pellón al monte en 1860, pero pasan casi un año en Fernando Poo antes de decidirse a acometer la empresa (Pajzderska 1893, 256).

Después de estos comentarios personales, la narradora relata la ascensión al pico Basilé (imagen 2). El 8 de enero de 1890 se ponen en camino, y el texto nos conduce a través de la isla mostrándonos a los habitantes de Santa Isabel, a los guías que acompañan a los exploradores - uno de los cuales dice llamarse Alfonso XII, que les cuenta su vida y les pide algo a cambio, gesto que genera un comentario irónico de la autora: "Alfonso XII nos aburrió contándonos su vida [...] Aparentemente, el título real le quedaba corto" (Pajzderska 1893, 269) -,${ }^{17}$ y a George Scott, un británico que ha buscado guías para ellos con el fin de que puedan subir por donde lo hizo Pellón, aunque pretende que ella se quede al pie de la montaña. Rogoziński no se inmuta y le cuenta que "la señora está dispuesta a morir en la cumbre" (270). ${ }^{18}$

${ }^{17}$ „Alfons X II nudził nas także, opowiadając szeroko dzieje swojego żyw ota. [...] Widocznie tytuł królewski skąpogo jakoś okryw ał”.

18 „«Missis» gotowa umrzeć na górze”. 


\section{IMAGEN 2. El matrimonio Rogoziński en su ascensión al pico Basilé}

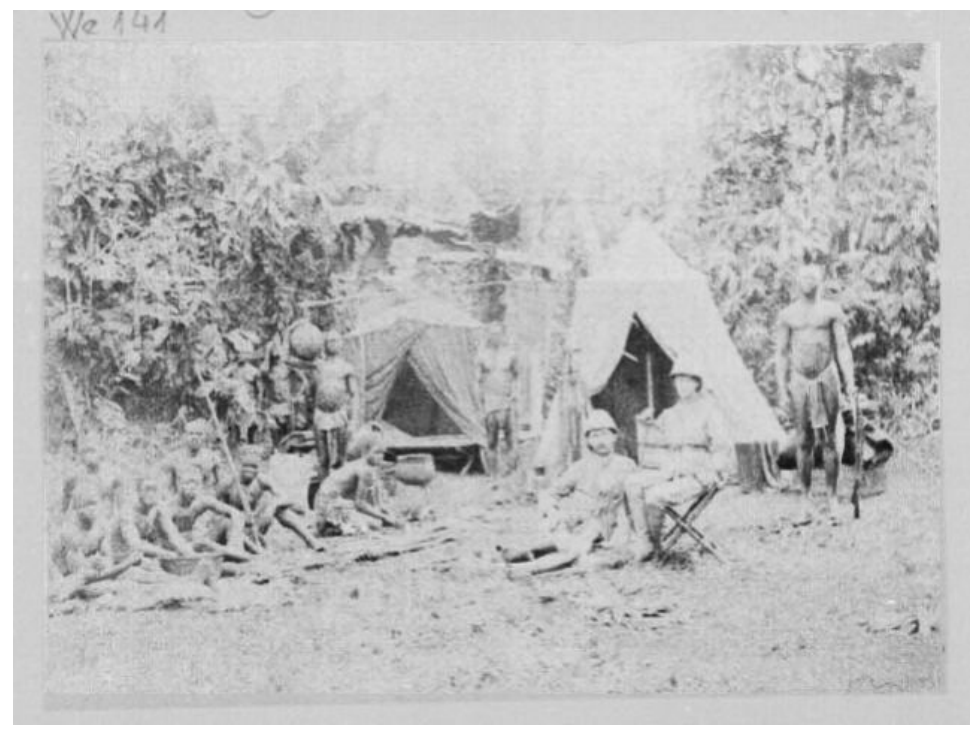

Fotografía de John Parkes Decker (1890).

La fotografía se conserva en la Bibliothèque nationale de France (https://catalogue.bnf.fr/ark:/12148/cb40589948n), y apareció publicada en La Ilustración Española el 22 de marzo de 1891, p. 189.

Asistimos con ella a una "palabra", un juicio local, que se eterniza y que "podría acabar con la paciencia del santo Job” (Pajzderska 1893, 273); ${ }^{19}$ describe la vegetación y lo que en Europa llaman "selva virgen”, que a ella le provoca una gran desilusión: "como alpinista y escaladora, acostumbrada a ascender a los picos a través de laderas abiertas, viendo tu objetivo frente a ti, me di cuenta de que no podía buscar las mismas impresiones y sentimientos en las cumbres montañosas

${ }^{19}$ „mogące samego Hioba do passyi doprowadzić”. 
de las tierras altas africanas"(277); $;{ }^{20}$ nos cuenta que un krumán le avisa antes de verse atacada por una colonia de hormigas; explica que ha visto plantas que producen caucho, lo cual supone una novedad, puesto que "hasta ahora se ha afirmado que en Fernando Poo no se producía caucho" (285); $;{ }^{21}$ habla de su resolución de llegar hasta la cima para contradecir a Scott y de cómo el guía local se pierde, "porque no conocía bien el camino y no quería admitirlo" (291).22

El paisaje, que describe con precisión, la lleva a imaginar la montaña como un fantástico decorado donde podría habitar Puck, el espíritu que sirve a Oberón en A Midsummer Night's Dream. Habla también de la organización jerárquica bubi, con el rey Moka a la cabeza, que acabó con las luchas entre los habitantes de los diferentes pueblos y que no quería saber nada de los blancos, "porque trajeron muchos males a Má-má-má-má, que es como los bubis llaman a la isla de Fernando Poo", ${ }^{23}$ aunque el gobernador de la isla hubiera intentado convencerlo de que enviara a sus hijos a la misión católica para que los educaran allí (Pajzderska 1893, 298). Hajota cuenta que sabe de dos blancos que han conocido al rey y Scott le responde que no se trata del rey, sino de su hermano, que acepta sin remilgos las visitas de los blancos (299).

El día 15 de enero de 1890 amanece soleado y claro, lo que les permite ver la bahía de Santa Isabel y la plantación que han comprado en la isla. Mientras siguen avanzando, llega un momento en que los guías tienen miedo de continuar y ella se adelanta, con el temor de que los abandonen allí:

${ }^{20}$ „Zrozumiałam także odrazu, jak alpinista i taternik co przywykł po otwartych skłonach wdzierać się na szczyty, widząc swój cel przed sobą, darmo by szukał znajomych wrażeń i uczuć górskich na grzbietach afrykańskich wyżyn”.

${ }^{21}$ „Dotychczas bowiem twierdzono powszechnie, że Fernando-Poó nie posiada wcale kauczuku”.

${ }^{22}$ „Nie znał on dobrze drogi i właśnie na tym skraju ją stracił, ale nie chciał się do tego przyznać".

${ }_{23}$ „Biali dużo złego ze sobą przynieść na Má-má-má-má (tak Bubusi nazywają wyspę Fernando-Poó)”. 
- ¡Chicos! —dije, mientras me dirigía sonriente hacia ellos-, ¿`osotros, $\tan$ fuertes y valientes, tenéis miedo de ir por donde va vuestra mami blanca? ¡Qué pena! ¡Mirad! Y sin esperar respuesta me deslicé entre los primeros arbustos del barranco. La medida funcionó (Pajzderska 1893, 307)..$^{24}$

Finalmente alcanzan la cumbre, donde descubren una botella envuelta en paño cubierta por unas piedras. Allí dejan un mensaje, escrito en inglés y en polaco. Mientras SzolcRogoziński recoge datos barométricos y termométricos, ella corta algunas plantas que después enviará a España como regalo para la reina regente (Pajzderska 1893, 310), un bouquet del que hablará más tarde la prensa madrileña. En el camino de vuelta recogen líquenes y musgo para el botánico polaco Anton Rehman, y cinco días después llegan a la primera aldea habitada, de donde habían salido 10 días antes. Pocos días más tarde, en presencia del gobernador, de los oficiales de marina y de los funcionarios civiles destinados a la isla, abren la botella que habían encontrado en la cima. Contiene dos documentos escritos en un papel amarillento:

Hoy el 3 de abril 1860 ha llegado a este punto Don Julián Pellón y Rodríguez Comisario Especial... [...] boca abajo, con un papel podrido, llado [sic] en un trapo, que se supone colocada por el antiguo Gobernador de la Isla Mr. Becroft... Se ruega la conservación de este apunto donde le deja su autor (en castellano en el original; Pajzderska 1893, 318).

La autora se disculpa, pues desconocía el contenido de la botella cuando la recogió, y supone que Pellón, "si hubiera vivido hasta ahora, no se habría enfadado con nosotros, aunque sólo fuera porque fue la mano de una mujer la que cometió esta indiscreción involuntaria y llevó a Europa la prueba de su valentía" (Pajzderska 1893, 319). ${ }^{25}$

${ }^{24}$ ”-Jakto chłopcy! —rzekłam, zwracając się do nich żartobliwie -wy, tacy silni i odważni, boicie się pójść, gdzie wasza biała mami idzie? To wstyd! Patrzcie! -i nie czekając na odpowiedź, zsunęłam się pomiędzy pierwsze krzaki przepaści. Środek poskutkował".

${ }^{25}$ „Myślę jednak, że gdyby żył dotąd, nie byłby nam wziął tego za złe, choćby 


\section{Conclusión}

Las expediciones europeas al África de finales del siglo XIX tenían un componente político evidente, además de su posible interés científico. En el caso que he estudiado, la expedición polaca al golfo de Guinea en 1882, las fuentes discuten si tenía por objetivo la fundación de una colonia polaca en Camerún o no. Aunque no hay acuerdo al respecto, lo que sí se puede comprobar a partir de los textos escritos por sus protagonistas y por personas ligadas a ellos es que las revistas científicas del momento se utilizaban con fines propagandísticos y que la información se dosificaba en función del público al que iba dirigida.

Szolc-Rogoziński no tuvo oportunidad de revisar sus publicaciones a causa de su temprana muerte, pero dos de las personas que le acompañaron en el camino, su compañero de expedición y su esposa, sí que lo hicieron. En el caso de Janikowski encontramos una reescritura mítica del pasado, ligada al nacionalismo polaco de los años treinta, que defiende la necesidad del establecimiento de colonias polacas en África, y considera su expedición de finales del siglo XIX como el primer paso hacia ese objetivo. En el caso de la novelista Hajota, la lectura del pasado es completamente diferente. No hay nostalgia colonial sino mera descripción literaria de los hechos vividos. Janikowski publicó sus memorias en un momento de exaltación patriótica polaca, truncado por la invasión nazi y el estallido de la Segunda Guerra Mundial, mientras que Pajzderska no se vio afectada por ese contexto. Sus publicaciones son, en ese sentido, completamente diferentes.

En cualquier caso, se trata de textos que muestran la pluralidad de voces presentes en el archivo colonial del global hispanophone, voces que van mucho más allá de las estudiadas tradicionalmente en el ámbito de los estudios hispánicos. El ze względu na to, iż to była ręka kobiety, która popełniła tę mimowolną niedyskrecją
i zaniosła do Europy dowód jego dzielności”. 
imperio español se extendía por América, Asia y África y tuvo multitud de conexiones internacionales que se expresaron en diversas lenguas, incluido el polaco, como hemos podido comprobar.

\section{Referencias}

BAgINSKi, Henryk. 1944. "The Sixtieth Anniversary of Rogozinski's Expedition to the Cameroons". The Geographical Journal 103, núms. 1-2: 72-75. https://doi.org/ 10.2307/1789068

BĘDKOwSKI, Mateusz. 2016. „Wyprawa Stefana Szolc-Rogozińskiego do Kamerunu a polskie marzenia o koloniach”. https://histmag. org/Wyprawa-Stefana-Szolc-Rogozinskiego-do-Kamerunu-apolskie-marzenia-o-koloniach-7403

Betley, Jan Andrzej. 1996. "Stefan Szolc Rogozinski and the Anglo-German Rivalry in the Cameroons". Journal of the Historical Society of Nigeria 5, núm. 1: 101-136. www.jstor.org/ stable/41856824

Campoy-Cubillo, Adolfo y Benita Sampedro Vizcaya. 2019. "Entering the Global Hispanophone: An Introduction". Journal of Spanish Cultural Studies 20, núms. 1-2: 1-16. https://doi.org/10. 1080/14636204.2019.1609212

Fernández Moreno, Nuria. 2013. "Bubi Government at the End of the 19th Century: Resistance to the Colonial Policy of Evangelization on the Island of Bioko, Equatorial Guinea”. Nordic Journal of African Studies 22, núms. 1-2: 23-48.

FRANCZYK, Bogusław. 2017. „Europejskie losy afrykańskiej wyspy - stacja na Mondoleh w źródłach historycznych”. En Ex Africa semper aliquid novi, editado por Jarosław Różański, 4: 56-72. Żory: Muzeum Miejskie w Żorach.

Guerra Velasco, Juan Carlos. 2018. “Una geografía imaginada: el Muni a través del proyecto de compañía de franquicia de Valeriano Weyler”. Estudios Geográficos 79, núm. 285: 347-374. https:// doi.org/10.3989/estgeogr.201813

HunczaK, Taras. 1967. "Polish Colonial Ambitions in the Inter-War Period”. Slavic Review 26, núm. 4: 648-656. https://doi.org/10. 2307/2492615. 
Hurlbut, George C. 1887. "Geographical Notes". Journal of the American Geographical Society of New York 19: 51-112. www. jstor.org/stable/196727

Janikowski, Leopold. 1886. "L'île de Fernando Poo. Son état actuel et ses habitants". Bulletin de la Société de géographie de Paris 7 , núm. 7: 563-589.

JaniKowski, Leopold. 1887a. "La isla de Fernando Poo. Su estado actual y sus habitantes". Revista de Geografía Comercial 43: 432-439. JaniKowski, Leopold. 1887b. "La isla de Fernando Poo. Su estado actual y sus habitantes". Revista de Geografía Comercial 45: 487491.

JANIKOWsKi, Leopold. 1936. W dżunglach Afryki. Wspomnienia z polskiej wyprawy afrykańskiej w latach 1882-1890. Varsovia: Ligi Morskiej i Kolonjalnej.

Knutson, Knut. 2002. Swedish Ventures in Cameroon, 1883-1923. Trade and Travel, People and Politics: The Memoir of Knut Knutson with Supporting Material. Editado por Shirley Ardener. Nueva York: Berghahn Books.

Nadolska-STYCZYŃsKa, Anna. 2007. „Kultury Afryki a działania naukowo-oświatowe Ligi Morskiej i Kolonialnej”. Prace Komisji Historii Nauki 8: 181-206.

Ossorio, Amado. 1886. "Fernando Poo y el golfo de Guinea. Apuntes de un viaje". Anales de la Sociedad Española de Historia Natural 15: 289-338.

PajzdersKa, Helena Janina. 1892. "Une ascension au pic Santa Isabel (Fernando Po)". Revue de géographie 30: 197-203, 287-295, 366-372.

PajZdersKa, Helena Janina. 1893. Z dalekich ladów. Nowele i opowiadania. Varsovia: Salomon Lewental.

Rhode, Maria. 2013. „Zivilisierungsmissionen und Wissenschaft. Polen kolonial?". Geschichte und Gesellschaft 39, núm. 1: 5-34. https://doi.org/10.13109/gege.2013.39.1.5

RóżAŃSKI, Jarosław. 2000. „Początki misji oraz pierwsze struktury kościelne w Kamerunie północnym". Saeculum Christianum. Pismo historyczno-społeczne 7, núm. 1: 83-116.

STUCKI, Andreas. 2012. Las guerras de Cuba. Violencia y campos de concentración (1868-1898). Madrid: La Esfera de los Libros.

Szolc-Rogoziński, Stefan. 1881. „Propozycją”. Wędrowiec 10, núm. 247: 188. 
Szolc-Rogoziński, Stefan. 1885. Voyage à la côte occidentale d'A frique dans la région des Cameroons. Conférence faite à la Société de géographie commerciale du Havre, le 24 novembre 1885. El Havre.

Szolc-Rogoziński, Stefan. 1886a. Pod równikiem. Odczyty S. S.

Rogozińskiego wypowiedziane w Sali Radnéj miasta Krakowa.

Cracovia: Drukarni „Czasu”.

Szolc-Rogoziński, Stefan. 1886b. Wyprawa S. S. Rogozińskiego.

Żegluga wzdtuż brzegów zachodniej Afryki na lugrze „Łucya-

Małgorzata” 1882-1883. Varsovia: Księgarnia A. Gruszeckiego.

Szolc-Rogoziński, Stefan. 1890. "El viajero polaco Rogozinski en

Fernando Poo". Boletín de la Sociedad Geográfica de Madrid 29: 60-72.

Iñaki Tofiño Quesada es profesor de secundaria y traductor. Licenciado en traducción por la Universitat Pompeu Fabra de Barcelona y máster en Literatura Comparada por la City University of New York y por la Universitat Autònoma de Barcelona. Actualmente está trabajando en una tesis sobre literatura colonial española. Ha publicado multitud de traducciones literarias y algunos artículos sobre literatura ecuatoguineana, traducción y poscolonialismo, censura y conflicto religioso, identidad LGBT en España y homosexualidad y educación.

$$
\begin{array}{r}
\text { https://orcid.org/0000-0003-3031-728X } \\
\text { ignaciotq@yahoo.com }
\end{array}
$$

